\title{
The effect of subauroral polarization streams on the mid-latitude thermospheric disturbance neutral winds: a universal time effect
}

\author{
Hui Wang ${ }^{1}$, Kedeng Zhang ${ }^{1,2}$, Zhichao Zheng ${ }^{1}$, and Aaron James Ridley ${ }^{3}$ \\ ${ }^{1}$ Dept. of Space Physics, School of Electronic Information, Wuhan University, Hubei, 430072, China \\ ${ }^{2}$ National Center for Atmospheric Research, Boulder, CO 80301, USA \\ ${ }^{3}$ Climate and Space Sciences and Engineering, University of Michigan, Ann Arbor, USA
}

Correspondence: Hui Wang (h.wang@whu.edu.cn)

Received: 24 October 2017 - Revised: 12 February 2018 - Accepted: 19 February 2018 - Published: 29 March 2018

\begin{abstract}
The temporal and spatial variations in thermospheric neutral winds at an altitude of $400 \mathrm{~km}$ in response to subauroral polarization streams (SAPS) are investigated using global ionosphere and thermosphere model simulations under the southward interplanetary magnetic field (IMF) condition. During SAPS periods the westward neutral winds in the subauroral latitudes are greatly strengthened at dusk. This is due to the ion drag effect, through which SAPS can accelerate neutral winds in the westward direction. The new findings are that for SAPS commencing at different universal times, the strongest westward neutral winds exhibit large variations in amplitudes. The ion drag and Joule heating effects are dependent on the solar illumination, which exhibit UT variations due to the displacement of the geomagnetic and geographic poles. With more sunlight, stronger westward neutral winds can be generated, and the center of these neutral winds shifts to a later magnetic local time than neutral winds with less solar illumination. In the Northern Hemisphere and Southern Hemisphere, the disturbance neutral wind reaches a maximum at 18:00 and 04:00 UT, and a minimum at 04:00 and 16:00 UT, respectively. There is a good correlation between the neutral wind velocity and $\cos ^{0.5}$ (SZA) (solar zenith angle). The reduction in the electron density and enhancement in the air mass density at an altitude of $400 \mathrm{~km}$ are strongest when the maximum solar illumination collocates with the SAPS. The correlation between the neutral wind velocity and $\cos ^{0.5}(\mathrm{SZA})$ is also good during the northward IMF period. The effect of a sine-wave oscillation of SAPS on the neutral wind also exhibits UT variations in association with the solar illumination.
\end{abstract}

Keywords. Ionosphere (ionosphere-atmosphere interactions; midlatitude ionosphere; plasma convection

\section{Introduction}

Neutral winds are known to be important in the ionospherethermosphere-magnetosphere coupling system due to the neutral drag effect (Rishbeth, 1967), the dynamo effect (Blanc and Richmond, 1980), as well as the flywheel effect (Deng et al., 1993; Ridley, 2005). Therefore, many studies have been conducted concerning neutral winds using both observations and simulations (Richmond and Matsushita, 1975; McCormac and Smith, 1984; Thayer et al., 1987; Emmert et al., 2002, 2006a, b; Richmond et al., 2003; Deng and Ridley, 2006; Lühr et al., 2007; Ritter et al., 2010; H. Wang et al., 2011, 2012a, 2017; Wu et al., 2014; Xiong et al., 2015; X. Zhang et al., 2017; S.-R. Zhang et al., 2017).

The global neutral wind in the $F$ region is driven by a combination of pressure gradients induced by local or global heating, ion drag, Coriolis and centrifugal forces, and upward-propagating atmospheric tides (Ridley et al., 2006). At high latitudes the ion drag force is considered to be the primary factor during quiet times (Thayer et al., 1987; Richmond et al., 2003; Lühr et al., 2007). The neutral wind patterns generally follow the direction of the plasma convection, exhibiting anti-sunward flow over the polar cap and sunward flow along the auroral oval (McCormac and Smith, 1984; Emmert et al., 2006a, b; Lühr et al., 2007). In addition, the neutral flow pattern can be modulated by Coriolis and viscous forces at high latitudes (Lühr et al., 2007). At mid-latitudes the quiet time neutral winds are mainly driven by the pressure gradient caused by the solar heating, resulting in the eastward flow from post-noon to early morning and the westward flow at all other times. During magnetic disturbed periods, the thermospheric neutral winds are highly disturbed due to Joule and particle precipitation heat- 
ing and enhanced plasma convection (Emmert et al., 2001, 2002; Xiong et al., 2015; Ritter et al., 2010; Wu et al., 2014; H. Wang et al., 2017). Interhemispheric comparisons of zonal neutral winds at mid-latitudes have been performed recently by using neutral wind observations at Palmer $\left(54^{\circ} \mathrm{S}\right.$ magnetic latitude, MLat, $64^{\circ} \mathrm{W}$ geographic longitude, GLon) and Millstone (53 ${ }^{\circ} \mathrm{N}$ MLat, $71.5^{\circ} \mathrm{W}$ GLon) (e.g., Wu et al., 2014; Deng et al., 2014). Wu et al. (2014) found more conjugacy during geomagnetically active periods when highlatitude effects became dominant. Deng et al. (2014) reported that the local time variation of neutral wind showed a very good conjugacy at equinox but not at June solstice, which was explained by the seasonal asymmetry of hemispheric polar activity. H. Wang et al. (2015) reported that the solar heating can explain the observed longitudinal variation of zonal neutral winds during quiet periods, based on Challenging Minisatellite Payload (CHAMP) observations and Global Ionosphere-Thermosphere Model (GITM) simulation. X. Zhang et al. (2017) conducted a comprehensive study on the global thermospheric zonal neutral winds' dependences on solar flux, geomagnetic activity, and hemisphere by using 7 years of CHAMP observations. They reported that the westward zonal neutral winds at subauroral latitudes were stronger under more sunlight conditions during both quiet and storm periods. In particular, previous work has disclosed that subauroral polarization streams (SAPS) can account for the westward disturbance neutral wind in the dusk-pre-midnight sectors at mid-latitudes, which have a flow direction opposite to the anti-sunward neutral winds induced by the pressure gradient caused by the solar heating, as has been previously reported (Emmert et al., 2001; H. Wang et al., 2011, 2012a, b; W. Wang et al., 2012; Zhang et al., 2015).

SAPS are one of the interesting and important features observed at mid-latitudes, and they have been investigated extensively by using both observations and simulations (e.g., Galperin et al., 1974; Smiddy et al., 1977; Yeh et al., 1991; Koustov et al., 2008; Kunduri et al., 2012, 2017; He et al., 2014, 2017; Yu et al., 2015; Califf et al., 2016). SAPS represent rapid westward plasma flow in the mid-latitudes in the dusk and pre-midnight sectors. The term SAPS was first introduced by Foster and Vo (2002) to encompass two different types of plasma flow: (1) the more intense and latitudinally narrower plasma flow, also known as subauroral ion drifts (SAID) or polarization jets (PJ) (Galperin et al., 1974); and (2) broader plasma flow with longer duration (Yeh et al., 1991). SAPS are driven by a strong poleward electric field located equatorward of the auroral oval, which is generated when the R2 field-aligned currents flow into the region of low conductance in the subauroral regions (Anderson et al., 1991). Other SAPS formation models have also been proposed to explain the rapid development of SAPS after substorm onset (Mishin et al., 2017). SAPS can alter the composition of the ionosphere, create an electron density trough, cause storm-enhanced density, and are related to plasmas- pheric plumes and erosions (Anderson et al., 1991; Foster and Vo, 2002; Spiro et al., 1978; Califf et al., 2016). Oksavik et al. (2006) presented the first two-dimensional observations of the variability of SAPS using mid-latitude Super Dual Auroral Radar Network (SuperDARN) radar located at Wallops Island. They found SAPS electric fields were highly variable on timescales of a few minutes. Koustov et al. (2008) reported SAPS evolution with substorm as observed by the Hokkaido East radar and compared it with theoretical simulations. Kunduri et al. (2012) found that the electric fields and latitudinal widths of SAPS showed hemispheric asymmetries by using mid-latitude SuperDARN radars with conjugate fields of view. The hemispheric differences were attributed to seasonal variations in the ionospheric conductivity and magnetic distortion effects in the inner magnetosphere. Kunduri et al. (2017) presented the first comprehensive statistical study of occurrence, location, and intensity of SAPS during both storm and non-storm periods by using measurements from the US mid-latitude SuperDARN radars. They found that SAPS occurred $15 \%$ of the time during quiet periods and $87 \%$ of the time during moderately disturbed conditions. They developed a new empirical model with Dst as input to estimate the occurrence probability of SAPS at a given magnetic latitude and magnetic local time (MLT). They also found a linear relationship between SAPS velocity and MLT during low and moderate levels of geomagnetic activities, but this relationship became nonlinear as the geomagnetic activity increased. They interpreted this behavior as the active feedback of the ionosphere and thermosphere playing an important role in modulating SAPS speeds. He et al. (2014) investigated the occurrence frequency, magnetic latitude, and width of SAID during different solar activity, season, and local time by using Defense Meteorological Satellite Program (DMSP) observations during 1987-2012. He et al. (2017) compared the time lag and lifetime of SAPS during substorm and storm periods. Yu et al. (2015) simulated SAPS by using a state-of-the-art magnetosphere model during the 17 March 2013 SAID event and compared it with observations. They found that the model showed an underestimate of the SAPS. The simulated SAPS penetrated deeper than observations, implying that the shielding from the Region 2 field-aligned currents in the model was not well represented. Califf et al. (2016) investigated SAPS during the 29 June 2013 geomagnetic storm in the equatorial plane with Van Allen probes. The relationships between plasma sheet ion and electron boundaries, and the spatial location of the SAPS, were investigated. They suggested that earthwardpropagating injections were driving the observed strong electric fields at low L levels in the equatorial magnetosphere. S.-R. Zhang et al. (2017) conducted a detailed study during the great geomagnetic storm on 17-18 March 2015 by using incoherent scatter radar observations at Millstone Hill and Arecibo and DMSP observations. They reported enhanced density plume, penetrating electric field, large ion tempera- 
ture enhancements, as well as upward ion drifts during the SAPS periods.

SAPS can drive westward neutral winds at the subauroral latitudes in the dusk sector due to the strong ion drag effect. By using coordinated CHAMP and DMSP satellite observations, H. Wang et al. (2011) studied the relationship between the SAPS and the upper thermospheric zonal neutral winds in the subauroral regions in the dusk and pre-midnight sectors. They found that both neutral wind and plasma velocities minimized at approximately the same latitude during SAPS periods. By applying the SAPS model to the Thermospheric Ionosphere Electrodynamics General Circulation Model (TIEGCM), W. Wang et al. (2012) modeled the effect of the SAPS on the thermosphere (temperature and neutral winds) and ionosphere (electron density), and confirmed that the strong ion drag effect caused by the SAPS could increase the neutral temperature in the subauroral and auroral regions and drive the large westward disturbance neutral winds in the SAPS region. They also found that the heating to the thermosphere by SAPS caused deeper and extended ionospheric electron density depletion. W. Wang et al. (2012) have not examined the universal time effect of SAPS on the thermosphere and ionosphere (neutral winds, air mass and electron density), which is the focus of the present work. H. Wang et al. (2012a) found that the SAPS' ion fluxes, a product of the SAPS ion velocity and ion density, exhibited similar seasonal variation to those of the zonal neutral winds. H. Wang et al. (2012b) found that the SAPS had the largest effect on neutral winds around 19:00 MLT, and the least effect around 23:00-24:00 MLT. They believed that this was related to the longer duration of SAPS events around 19:00 MLT than at other times. Based on observations from the Millstone Hill incoherent scatter radar and Fabry-Perot interferometers, Zhang et al. (2015) reported that during SAPS periods the westward neutral winds could establish a poleward neutral wind surge due to the poleward Coriolis force. X. Zhang et al. (2017) found subauroral westward jets during storm periods based on CHAMP observations.

The ion drag force and Joule heating depend on the electron density $(\mathrm{Ne})$ and ionospheric conductivity. The electron density at fixed magnetic latitude bands varies with the universal time (UT) due to the displacement of the geographic and geomagnetic poles. Such UT effects during magnetic storms and substorms have been reported in the literature. Roble et al. (1982) found that both meridional and zonal disturbed neutral winds attained peaks around 18:00 and 06:00 UT in the Northern Hemisphere and Southern Hemisphere, respectively, during storm periods. Fuller-Rowell et al. (1994) determined that atmospheric disturbances traveling from polar latitudes to lower latitudes reached their maximum propagation speeds in the near magnetic pole longitudinal region on the nightside. Perlongo and Ridley (2016) concluded that the air mass density and temperature were highest when the maximum solar ionization occurred in the same location as the high-latitude potential pattern. $\mathrm{H}$. Wang et al.
(2017) showed that during substorms the disturbed neutral winds at the high latitudes exhibited large variations with UT. Due to the presence of more solar illumination in the auroral oval, stronger disturbed neutral winds could be generated.

In this study we investigate the thermospheric disturbance neutral winds in response to the presence of SAPS occurring at different universal times by using a sophisticated global ionosphere-thermosphere model. Instead of focusing on the magnetosphere-ionosphere coupling, this study focuses on the ionosphere-thermosphere coupling during SAPS periods.

\section{Model}

The GITM was developed at the University of Michigan. The GITM is a three-dimensional model that simulates ionospheric and thermospheric dynamics (Ridley et al., 2006). The continuity, momentum, and energy equations are solved for the thermosphere and ionosphere using realistic source terms. The GITM solves the neutral momentum equation by considering the pressure gradients, ion drag, viscous force, and Coriolis force. It is driven by the solar extreme ultraviolet (EUV) radiation, high-latitude electric field (Weimer, 2005), precipitation of auroral particles (Fuller-Rowell and Evans, 1987), and the tides at the lower boundary (Hagan et al., 1999). The magnetic topology is described by the international geomagnetic reference field (IGRF) (Maus et al., 2005). However, we have to note that the ionosphere and thermosphere model used in the present work does not take into account the potential effect of the ionospheric conductivity feedback on the inner magnetospheric electric fields. Future work will use a coupled magnetosphere, ionosphere and thermosphere model that includes SAPS to investigate the electrodynamic effect on the neutral winds in a selfconsistent way.

Several studies have used the GITM for ionospherethermosphere physical studies, and good agreements were achieved when model outputs were validated with observations and other modeling results (e.g., Pawlowski and Ridley, 2008; A Ercha et al., 2012; Zhu and Ridley, 2014; H. Wang et al., 2015, 2016, 2017; Liu and Ridley, 2015; Perlongo and Ridley, 2016). Deng and Ridley (2006) validated the neutral winds within the model by using the Wind Imaging Interferometer instrument observation, and showed that the simulated neutral winds were consistent with the observations. $\mathrm{H}$. Wang et al. (2016) investigated longitudinal differences in thermospheric zonal neutral winds in the subauroral region for different seasons and under solar maximum and medium conditions by using CHAMP observations and GITM simulations. They found that the model results confirmed observed results in large-scale structures, and the local time and hemispheric asymmetries of the peak differences were consistent with CHAMP observations. However, the model underestimated the observed longitudinal differences of the zonal neutral wind. H. Wang et al. (2017) studied the tem- 
Potential (kv)

21-MAR-00

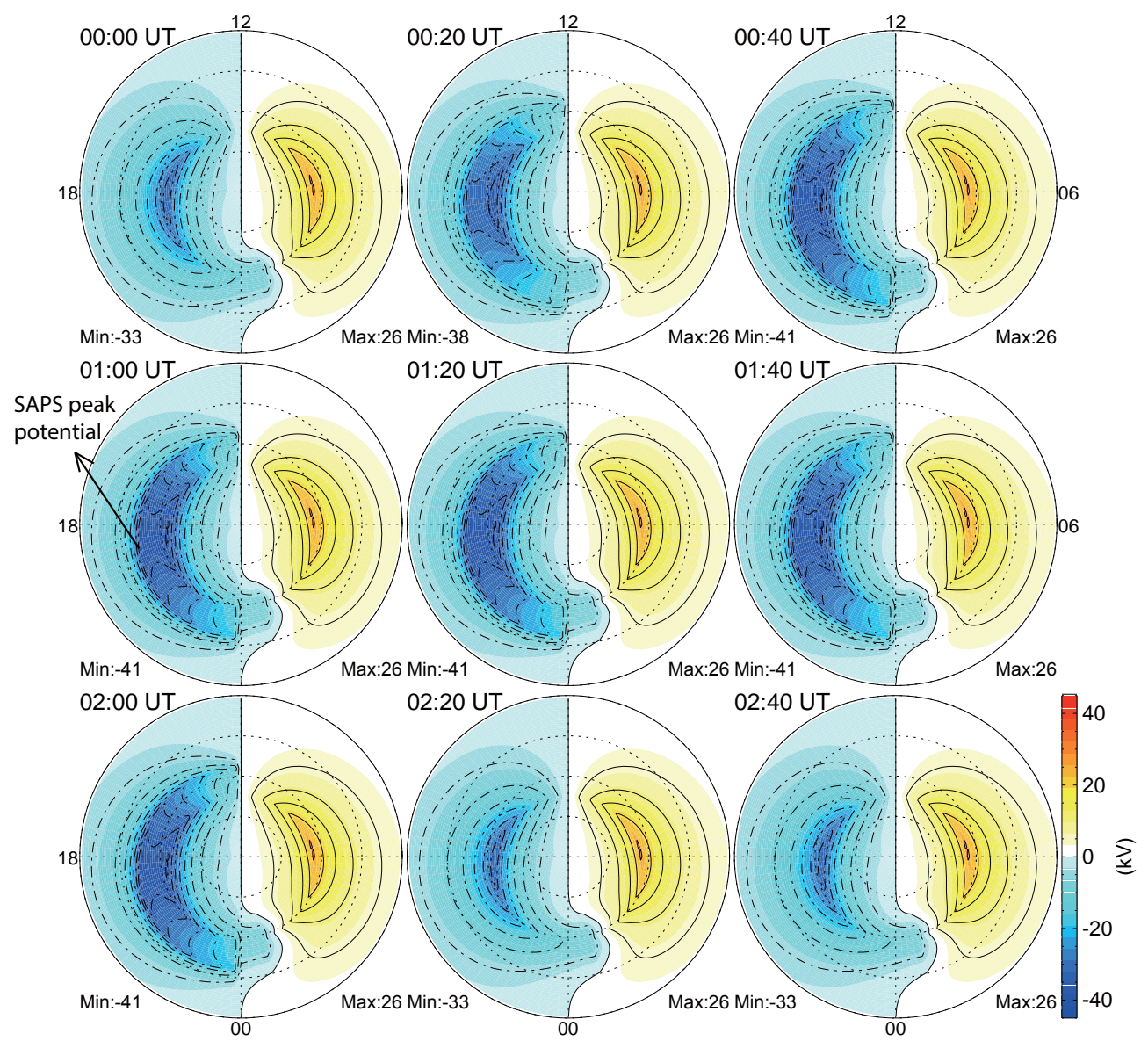

Figure 1. Geomagnetic latitude and magnetic local time variation of the ionospheric electrical potential. The outer ring represents $50^{\circ} \mathrm{MLat}$. The substorm epoch time runs at $20 \mathrm{~min}$ intervals from $-1 \mathrm{~h}$ to $2 \mathrm{~h} 40 \mathrm{~min}$. Noon is at the top of each panel. Midnight is at the bottom. Dawn is to the right and dusk to the left. SAPS potential is located $7^{\circ}$ equatorward of the boundary of the auroral oval. SAPS potential increases linearly from 00:00 to 00:30 UT, and then persists from 00:30 to 02:00 UT. SAPS potential reaches a minimum of $-24 \mathrm{kV}$ around 19:00 MLT, and decreases towards noon and midnight. SAPS potential is superimposed on the background potential in the subauroral region. The maximum and minimum potentials in the auroral and subauroral regions are shown at the bottom of each plot.

poral and spatial variation in thermospheric neutral winds at $400 \mathrm{~km}$ altitude in response to substorms by using CHAMP observations and GITM simulations. They found that the substorm time neutral wind amplitudes from the model were underestimated, especially at dawn when compared to observations. They proposed several reasons for explanation of the model-observation differences. The cross-track neutral winds observed by CHAMP were predominantly in the geographic zonal direction due to its high-inclination orbit, not in the magnetic zonal direction. This could somewhat affect the comparison with GITM results. Model resolution could affect the magnitudes of outputs. Deng and Ridley (2006) found that when the latitudinal resolution changed from $5^{\circ}$ to $1.5^{\circ}$, the neutral gas heating rate could increase by $20 \%$, because the model could better capture small-scale electric field and particle precipitation.

The GITM was run with a resolution of $2^{\circ}$ latitude and $10^{\circ}$ longitude for altitudes of 100 to $600 \mathrm{~km}$. A quasi-steady state was reached after the model was run for $48 \mathrm{~h}$. After the steady state was reached, the simulations were run for another $24 \mathrm{~h}$, the data of which were used for our study. The input parameters for the March 2000 equinox were as follows: IMF $B_{\text {xgse }}=0 \mathrm{nT}, B_{\text {ygse }}=0 \mathrm{nT}, B_{\mathrm{zgse}}=-2 \mathrm{nT}$, solar wind velocity, $V_{\mathrm{xgse}}=-400 \mathrm{~km} \mathrm{~s}^{-1}, \mathrm{~F} 10.7=100 \mathrm{sfu}$, and hemispheric power $(\mathrm{HP})=20 \mathrm{GW}$. The tropospheric tides were turned off in order to focus on the in situ physical processes. 

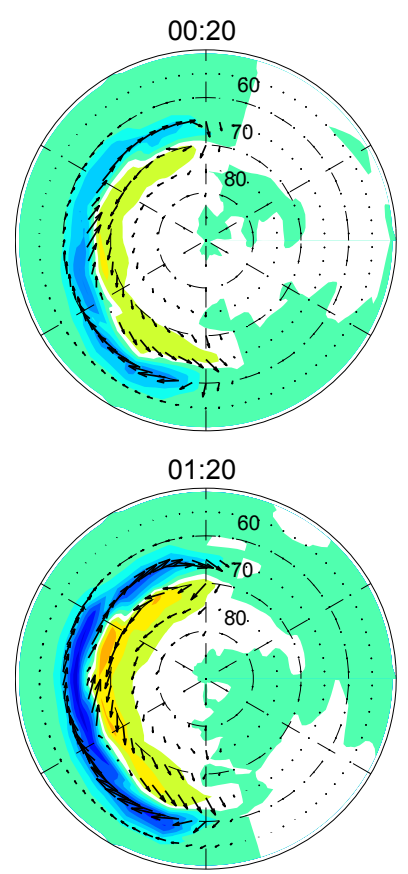

$00: 40$

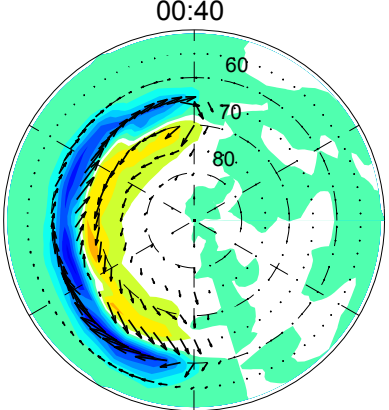

$01: 40$

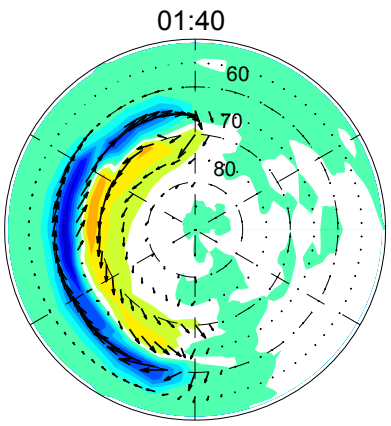

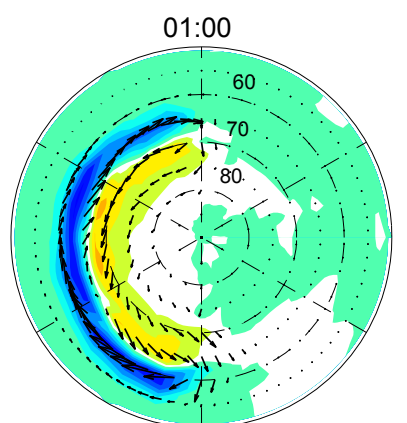

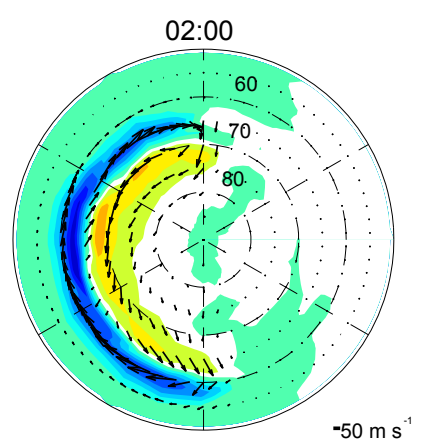

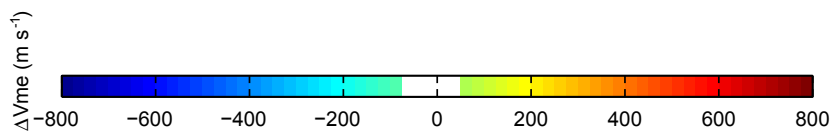

Figure 2. Geomagnetic latitude and magnetic local time variation of the plasma flow in the Northern Hemisphere from 00:20 to 02:00 epoch times. Each panel is the difference between the plasma velocity at the panel UT and the plasma velocity $24 \mathrm{~h}$ earlier. Vectors are shown with black arrows, and the zonal velocity is shown in color. Negative values represent westward plasma flow.

Figure 1 shows the polar maps of the ionospheric potential for an ideal run, which was used as input to the GITM in the magnetic latitude and local time coordinate system. The same potentials were applied to both the Northern Hemisphere and Southern Hemisphere, because Anderson et al. (2001) showed that the SAPS electric field was almost conjugate in both hemispheres. The SAPS for this model run occurred at 00:00 UT. The potential maps shown are for 00:00 to $02: 40$ UT with a $20 \mathrm{~min}$ time interval. The typical positive and negative potential cells can be seen in the polar cap region during the southward IMF period. SAPS are latitudinal narrow regions of intense westward flows and are considered to result from poleward directed subauroral electric fields (Anderson et al., 2001; Foster and Vo, 2002; Oksavik et al., 2006; Kunduri et al., 2012). In the subauroral region, we artificially add a negative potential to the background potential. It results in a poleward electric field in a subauroral region and a westward plasma flow, i.e., SAPS. The SAPS potential is set to minimize around 19:00 MLT and gradually approached zero towards noon and midnight, which is consistent with the most probable local time of SAPS from previous observational work (H. Wang et al., 2008; He et al., 2014). In the simulation during the southward IMF pe- riod, the open closed boundary of the auroral oval is around $72^{\circ}$ MLat at 19:00 MLT. The SAPS potential is set to minimize at $7^{\circ}$ MLat equatorward of the open closed boundary of the auroral oval, and a latitudinal width of $2^{\circ}$ (see the maps from 00:20 to 02:00 UT). This makes SAPS minimize around $65^{\circ}$ MLat at 19:00 MLT, which is equatorward of the auroral oval (the electron density pattern around $150 \mathrm{~km}$ altitude is not shown). The SAPS MLat is within the range of previous statistical results (H. Wang et al., 2008). By using 2 years of DMSP ion drift meter measurements, H. Wang et al. (2008) found that SAPS peaked between $62^{\circ}$ and $66^{\circ}$ MLat when $\mathrm{Kp}<3$, depending on the ionospheric conductivity condition. The SAPS potential varied linearly from 0 to $-24 \mathrm{kV}$ within half an hour, and remained at $-24 \mathrm{kV}$ for another $1.5 \mathrm{~h}$ (from 00:30 to 02:00 UT), after which the SAPS potential was set to zero.

Figure 2 shows the plasma velocity of the disturbance on the polar map at an altitude of $400 \mathrm{~km}$. The SAPS for this event occurred at 00:00 UT, and 00:00 epoch time marks the onset time of the SAPS. The plasma velocity of the disturbance is defined as $\Delta \mathrm{Vi}=\mathrm{Vi}_{\text {saps }}-\mathrm{Vi}_{\text {nosaps }}$, where $\mathrm{Vi}_{\text {saps }}$ is the plasma velocity during SAPS periods, and $\mathrm{Vi}_{\text {nosaps }}$ is the pattern during no-SAPS periods at the same UT but $24 \mathrm{~h}$ 

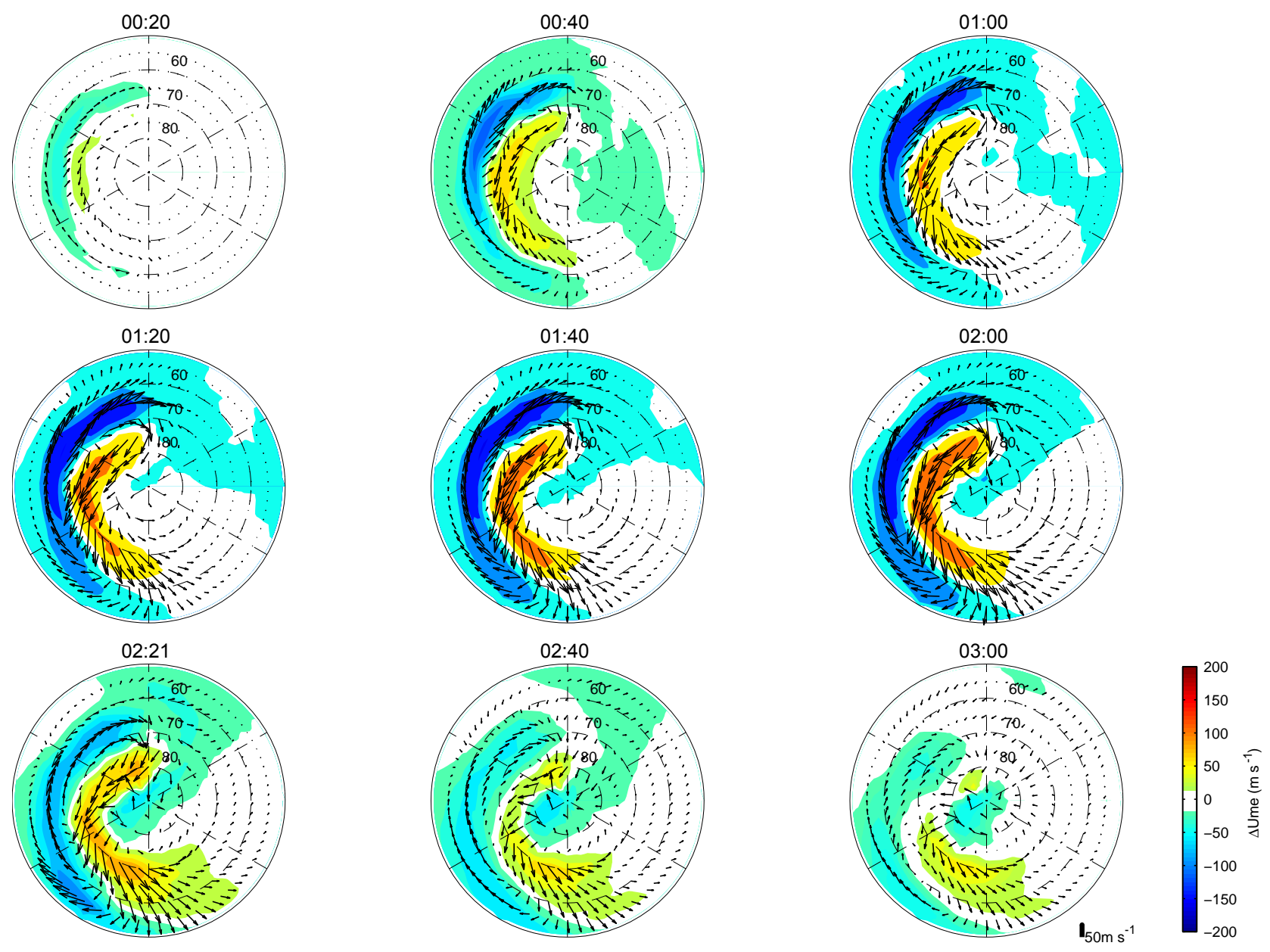

Figure 3. Geomagnetic latitude and magnetic local time variation of the disturbance neutral zonal wind in the Northern Hemisphere from 00:20 to 03:00 epoch time. The wind velocity at the same UT but 24 h earlier has been subtracted in each panel. Vectors are shown with black arrows, and the zonal velocity is shown in color. Negative values represent westward neutral wind flow.

earlier. The horizontal plasma velocity vectors are shown as black arrows. The zonal disturbance velocity is depicted by colored contours. Negative values represent westward deflection. In Fig. 2, the strong westward plasma flow is present as a result of the imposed SAPS potential equatorward of the auroral oval boundary in the dusk sector. The latitude of the SAPS decreases with increasing MLT. The MLT dependence of the SAPS have been reported from observations in the literature (Foster and Vo, 2002; Clausen et al., 2012; Kunduri et al., 2017). The SAPS amplitudes decrease from 00:00 UT to 00:30 UT, and remain at their minimum $\left(-720 \mathrm{~km} \mathrm{~s}^{-1}\right)$ for another $1.5 \mathrm{~h}$. The SAPS disappeared after 02:00 UT. There is another eastward drift channel located poleward of the SAPS, which is caused by the imposed negative potential. This eastward flow could weaken the regular sunward or westward plasma flow in the auroral oval.

\section{Simulation results}

\subsection{Disturbance neutral winds}

Figure 3 shows the disturbance neutral winds in the Northern Hemisphere at an altitude of $400 \mathrm{~km}$ simulated by the GITM, which has the same format as Fig. 2. The disturbance neutral winds are the differences between the SAPS runs and the no-SAPS runs. The neutral wind velocities are shown in the quasi-dipole (QD) coordinates system (Richmond, 1995; Emmert et al., 2010): $U_{\mathrm{mn}}=U_{\mathrm{gn}} \cdot \cos D+U_{\mathrm{ge}} \cdot \sin D, U_{\mathrm{me}}=$ $-U_{\mathrm{gn}} \cdot \sin D+U_{\mathrm{ge}} \cdot \cos D$, where $U_{\mathrm{gn}}, U_{\mathrm{ge}}$ are the meridional and zonal velocities in the geographic coordinate system, $U_{\mathrm{mn}}, U_{\mathrm{me}}$ are the meridional and zonal velocities in the QD coordinate system, and $D$ is the angle between the magnetic meridian and geographic north.

It can be seen that strong westward neutral winds develop from noon to midnight in the subauroral region. The west- 
(a) $\mathrm{NH}$, duskside (12-24 MLT)

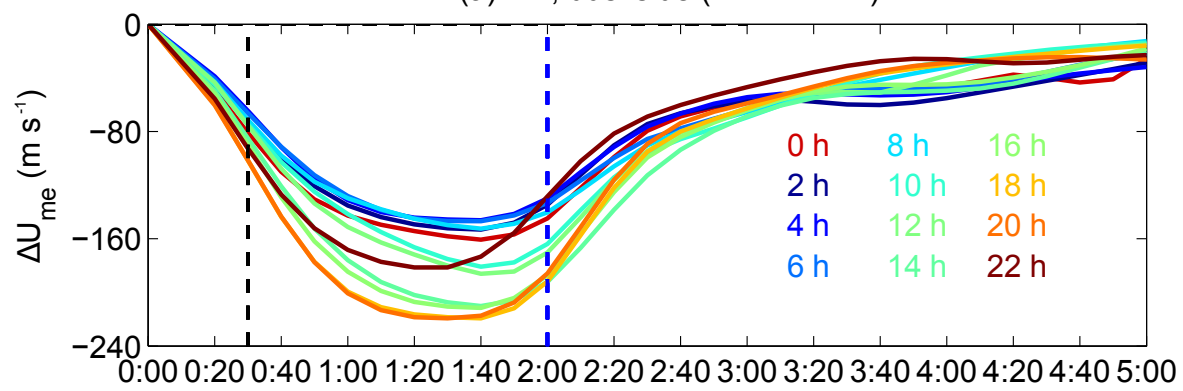

(b) $\mathrm{SH}$, duskside (12-24 MLT)

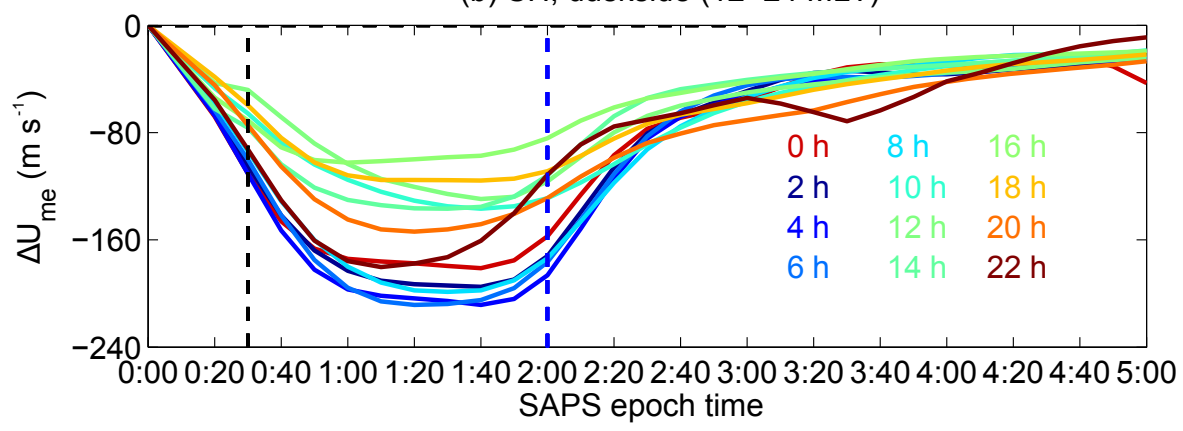

Figure 4. Time variation of the strongest disturbance neutral wind in the dusk sector (18:00-24:00 MLT). Different colors represent SAPS onset times at $2 \mathrm{~h}$ intervals from 00:00 to 22:00 UT. The SAPS potential attains extreme values around 00:30 epoch time, as indicated by the black vertical dashed line. SAPS become zero around 02:00 epoch time, as indicated by the blue vertical line. The top panel is for the Northern Hemisphere, and the bottom panel is the Southern Hemisphere.

ward neutral winds are aligned with the SAPS channel with larger latitudinal extent, and are driven by the SAPS due to the strong ion drag effect. The SAPS effect on the thermospheric neutral winds has been examined by $\mathrm{H}$. Wang et al. (2011) using coordinated CHAMP and DMSP observations. It was found that SAPS could cause strong westward neutral winds with larger latitudinal extent than SAPS. CHAMP observed westward neutral winds with a velocity of about $-215 \mathrm{~m} \mathrm{~s}^{-1}$ inside the zone of SAPS with a velocity of $-710 \mathrm{~m} \mathrm{~s}^{-1}$ when $\mathrm{Kp}<4$ (see Table 1 in $\mathrm{H}$. Wang et al., 2011). Our results are qualitatively in agreement with the CHAMP observations, but the neutral wind velocity seems to be underestimated in the model. The strongest neutral winds can be found at 01:40 epoch time with a speed of $-163 \mathrm{~m} \mathrm{~s}^{-1}$ at 15:00 MLT and $65^{\circ}$ MLat, which is $50 \mathrm{~min}$ after the SAPS reached their minimum value around $-710 \mathrm{~m} \mathrm{~s}^{-1}$. The modeled neutral wind speed is about $50 \mathrm{~m} \mathrm{~s}^{-1}$ weaker than the observation. The disturbance neutral winds did not recover as quickly as SAPS (see the 02:20, 02:40 and 03:00 epoch times). There were eastward disturbance neutral winds located poleward of the westward neutral winds. These eastward neutral winds could decrease the traditional westward neutral winds in the auroral oval in relation to the plasma convection flow. Such eastward neutral winds in the auroral oval are also reproduced by W. Wang et al. (2012).

\subsection{UT variations}

In the model, the SAPS were artificially set to commence at different universal times, at an interval of $2 \mathrm{~h}$ from 00:00 to 22:00 UT on 21 March 2000. Twelve isolated SAPS runs were conducted for different UT times, and they all lasted for $5 \mathrm{~h}$. Polar maps of the disturbance neutral winds were produced for each SAPS event using the same format as Fig. 3. The peak westward neutral winds at each SAPS epoch time were identified and recorded.

The variations of the peak westward neutral winds with epoch time are illustrated in Fig. 4, where 00:00 epoch time is the onset time of the SAPS. Different colors denote SAPS events that occur at different UT times. As shown in Fig. 2, the SAPS minimize at 00:30 epoch time (as indicated by the vertical black line), and disappear at 02:00 epoch time (as indicated by the vertical blue line). For all SAPS events, the westward neutral winds attain their minimum approximately 50-90 min later, and they recover more slowly than the SAPS due to the neutral inertia effect. S.-R. Zhang et al. (2017) found the timescale of approximately an hour following the onset of strong ion flow relative to the neutrals. 
We conclude that the velocities of the disturbance neutral winds differ greatly when the SAPS occur at different UTs. In the Northern Hemisphere, a strongest disturbance neutral wind velocity of about $-222 \mathrm{~m} \mathrm{~s}^{-1}$ is achieved when the SAPS start at 18:00 UT, while the weakest neutral wind velocity of $-147 \mathrm{~m} \mathrm{~s}^{-1}$ occurs at 04:00 UT. However, in the Southern Hemisphere, the strongest velocity of $-214 \mathrm{~m} \mathrm{~s}^{-1}$ tends to occur at 04:00 UT, and the weakest value of $-104 \mathrm{~m} \mathrm{~s}^{-1}$ occurs at 16:00 UT. Note that the imposed SAPS potential is the same for all events. Such UT variations may be related to the solar illumination effect in the SAPS regions, which will be addressed in more detail in the Discussion section.

\subsection{MLT distribution}

As introduced in Sect. 2, the SAPS potential was artificially forced to minimize at 19:00 MLT and to decrease towards both noon and midnight. The strongest westward disturbance neutral winds in each MLT bin at 01:20 epoch time were selected out. Figure 5 shows the MLT variations of these strongest westward neutral wind velocities. The different colors represent SAPS events that occur at different UTs. We conclude that the neutral winds tend to locate at an earlier local time for weaker disturbance neutral wind velocity, and vice versa. For example, in the Northern Hemisphere, the strongest neutral winds locate at approximately 16:00 MLT for SAPS occurring at 18:00 UT, while the weakest neutral winds are found around 14:00 MLT for SAPS starting at 04:00 UT.

\section{Discussion}

\subsection{SAPS effects on neutral winds}

In the previous section we discuss the variations in the zonal neutral winds when SAPS are included in the model. In the SAPS-GITM run, the westward neutral winds in the subauroral region are reproduced in the dusk sector. This can be attributed to the ion drag effect through which the SAPS drive the neutral winds in the westward direction. Our simulation results are consistent with previous observations and simulation results. Based on observations made by Dynamics Explorer 2 during the 24 November 1982 magnetic storm, Miller et al. (1990) concluded that there were strong SAPS and enhanced westward neutral winds during that event. Based on 2 years of coordinated CHAMP and DMSP observations, H. Wang et al. (2011) investigated the relationship between the SAPS, the electrojet, the zonal neutral wind and the mass density. They determined that the zonal neutral winds streamed westward in the same direction as the SAPS equatorward of the high-conductivity channel. Both the neutral winds and the plasma flows minimized at the same latitude. X. Zhang et al. (2017) reported stronger subauroral westward jets during storm time from CHAMP observations, which was not shown in the empirical global geomagnetic disturbance wind model (DWM07). W. Wang et al. (2012) incorporated an empirical model of SAPS into the TIEGCM and simulated the effect of SAPS on the global thermosphere and ionosphere during a moderately geomagnetically active period. They found that the SAPS caused large westward neutral winds at higher altitudes in the afternoon-midnight sector. Our model work is different from that of W. Wang et al. (2012), mainly in two ways: (1) W. Wang et al. (2012) imposed the SAPS velocity on the TIEGCM, while we used the GITM imposed by the SAPS potential. (2) W. Wang et al. (2012) were concerned about the effect of SAPS on the zonal neutral winds, while we focused on the UT variations of such an effect.

In this study, it is quite interesting to note that although the SAPS potential is fixed in all cases, the resulting westward neutral wind velocities vary greatly in amplitude and are concluded to depend on the universal time when SAPS start to occur. The strength of the ion drag is proportional to the magnitude of the ionospheric electron density. H. Wang et al. (2012a) concluded that there was a good linear relationship between the SAPS' westward ion flux and the zonal neutral wind, which highlighted the important role of the background electron density. Thus, it is speculated that the background electron density in the SAPS region might exhibit UT variations, which would account for the UT variations of the ion drag force.

The electron density of the subauroral region depends on the solar ionization, because the particle precipitation is mainly confined to the auroral region. Other factors that can affect the spatial distribution of the electron density include the transport from the electric fields and neutral winds and neutral composition ratios (H. Wang et al., 2015). The solar illumination at fixed local times on the dayside is related to the solar zenith angle (SZA), which is related to the geographic latitude (GLat). The GLat of the fixed subauroral magnetic latitude can exhibit obvious variation with longitude or UT, and thus different levels of sunlight. For example, in the Northern Hemisphere, at $60^{\circ}$ MLat and 15:00 MLT, the SZA attains a minimum of $59.6^{\circ}$ at $18: 00 \mathrm{UT}$, and a maximum of $75.6^{\circ}$ at 04:00 UT. This means that the subauroral region receives the largest amount of solar illumination at 18:00 UT and the smallest amount at 04:00 UT. Therefore, the ion drag force is strongest at 18:00 UT and weakest at 04:00 UT in the Northern Hemisphere for the same SAPS potential at both UTs. This explains the stronger zonal neutral winds that occur when the SAPS start at 18:00 UT and the weaker zonal neutral wind when SAPS initiate at 04:00 UT. In the Southern Hemisphere, at $-60^{\circ}$ MLat and 15:00 MLT, the SZA attains a minimum of $57.6^{\circ}$ at 04:00 UT, and a maximum of $82.9^{\circ}$ at 16:00 UT. This corresponds to the SAPS onset times when the maximum and minimum zonal neutral winds are generated. Wu et al. (2014) found that the TIEGCM with a SAPS model reproduced stronger westward neutral winds between 00:00 and 07:00 UT in the Southern 
(a) $\mathrm{NH}$, duskside (12-24 MLT)

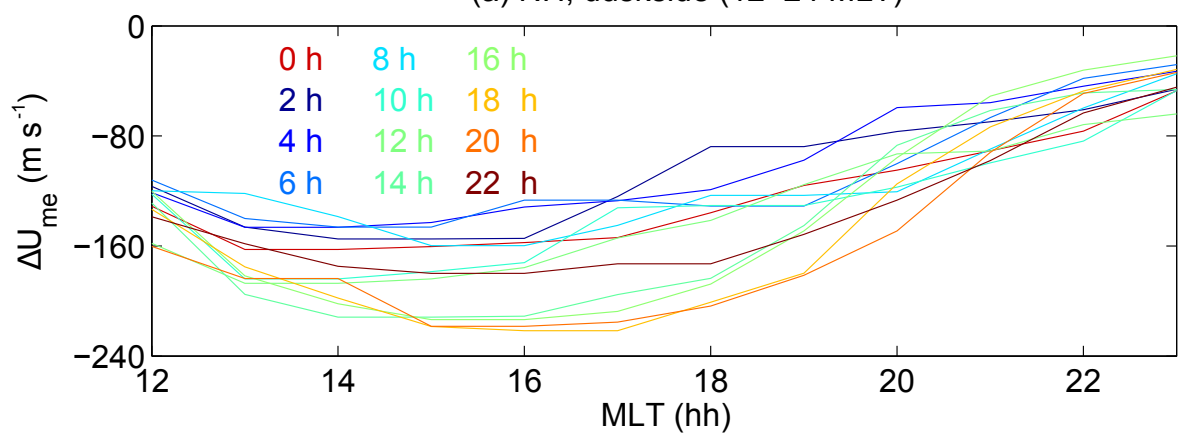

(b) SH, duskside (12-24 MLT)

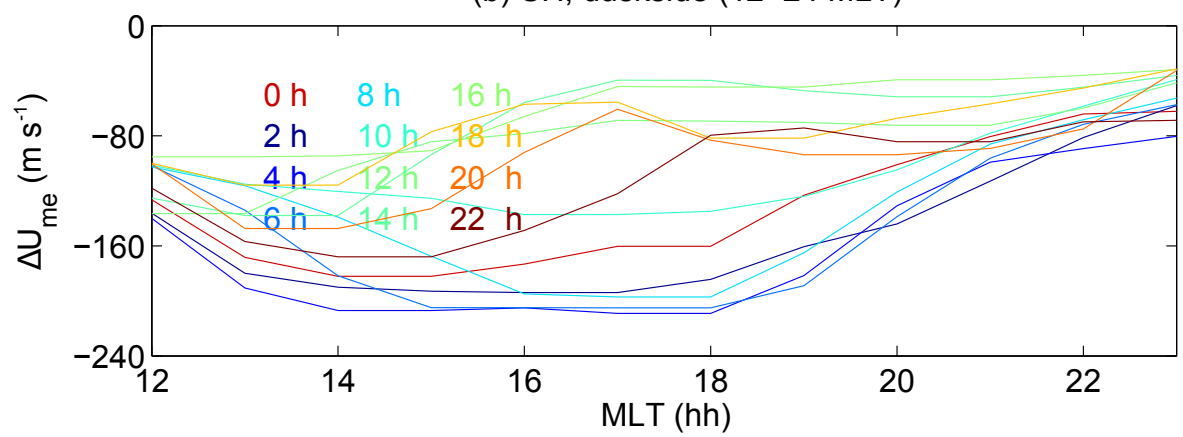

Figure 5. The MLT variation of the strongest disturbance westward neutral winds driven by SAPS. Different colors represent SAPS onset times from 00:00 to 22:00 UT at $2 \mathrm{~h}$ intervals. The top panel is in the Northern Hemisphere, and the bottom one in the Southern Hemisphere.
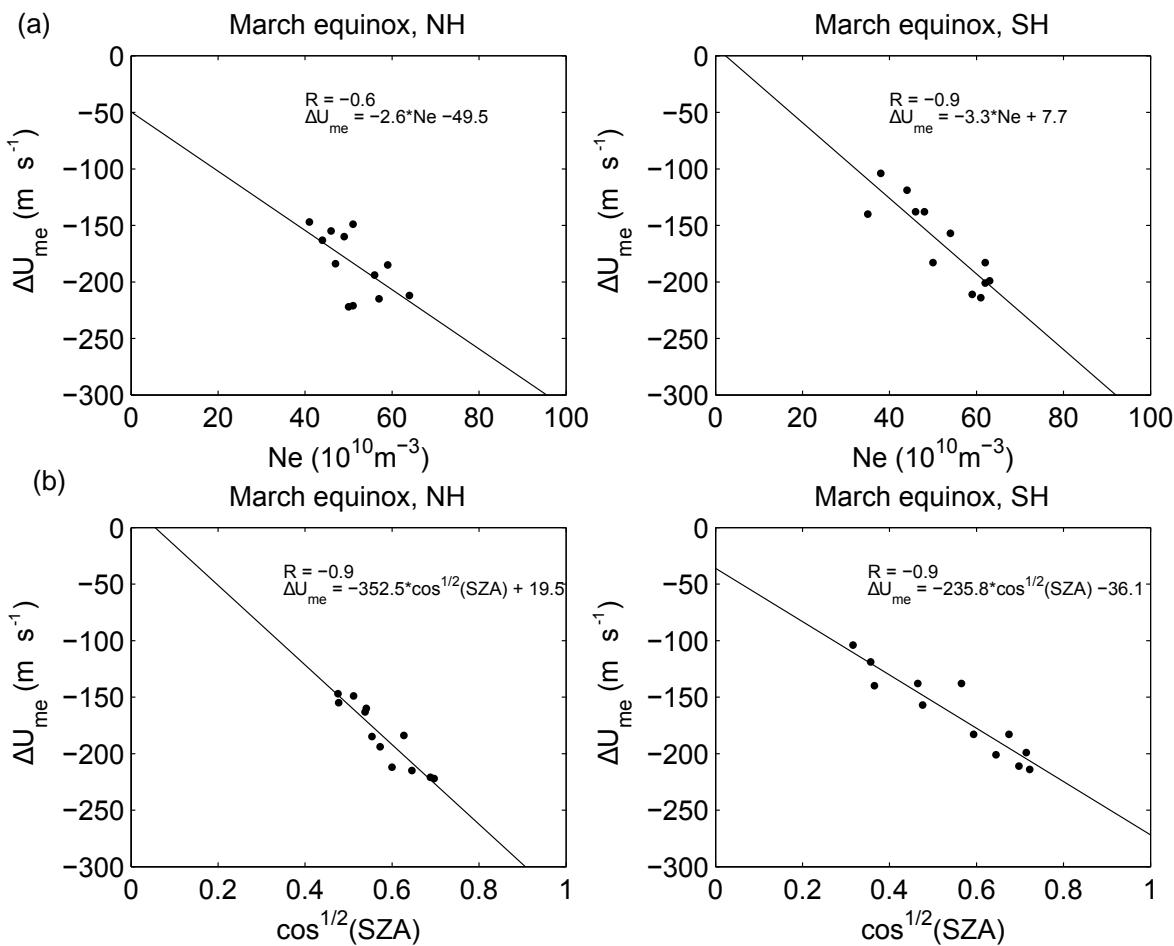

Figure 6. The top row shows the correlation between the strongest westward disturbance neutral wind with peak electron density in both hemispheres. The bottom row shows the correlation between the strongest westward disturbance neutral wind with $\cos ^{1 / 2}(\mathrm{SZA})(\operatorname{solar}$ zenith angle, SZA) in both hemispheres. The correlation coefficient $(R)$ and linear relationship between the parameters are shown in each plot. 
Hemisphere but lesser westward neutral wind in the Northern Hemisphere. This is consistent with our model result that the zonal neutral wind is strongest at 04:00 UT in the Southern Hemisphere and weakest at 04:00 UT in the Northern Hemisphere. Thus, we think that the solar illumination effect might explain the hemispheric asymmetry of the zonal wind in response to SAPS as shown in Wu et al. (2014). Our conclusions that the solar illumination can affect the strength of the zonal winds are consistent with previous observation and model studies (e.g., H. Wang et al., 2015; X. Zhang et al., 2017). H. Wang et al. (2015) found that solar illumination could explain the longitudinal UT variation of zonal winds at subauroral regions during quiet periods by using CHAMP observations and GITM simulations. X. Zhang et al. (2017) reported that the quiet and storm time zonal winds at subauroral latitudes were influenced by solar illumination conditions by using several years' CHAMP observations. They found that both the quiet time and storm-induced subauroral westward neutral winds were stronger in the summer hemisphere. As outlined in Sect. 3.3, the local time periods in which the disturbance neutral winds attain their extreme values exhibit UT variations. This may be related to the variation in the area of the solar illumination with UT. For example, the illumination region will shift more towards the dayside at 04:00 than at 18:00 UT in the Northern Hemisphere, and more toward the dayside at 16:00 UT than at 04:00 UT in the Southern Hemisphere. Thus, the strongest disturbance neutral winds tend to locate at an earlier local time at 04:00 than at 18:00 UT in the Northern Hemisphere, while they tend to locate earlier at 16:00 than at 04:00 UT in the Southern Hemisphere.

The strongest westward neutral winds are identified from Fig. 4 for 12 SAPS simulation cases that occur at 12 different UT times. According to Chapman's theory (Schunk and Nagy, 2004), the Ne due to solar illumination is proportional to $\cos ^{1 / 2}(\mathrm{SZA})$. Fig. 6 shows the correlation between the strongest westward neutral wind velocities and the Ne (top panel), and $\cos ^{1 / 2}$ (SZA) (bottom panel). The SZA is calculated at $\pm 60^{\circ}$ MLat and 15:00 MLT (representing the subauroral region in the dusk sector), in the Northern Hemisphere and Southern Hemisphere, respectively. The quantitative relationships between the strongest disturbed neutral winds and the $\mathrm{Ne}$, and $\cos ^{1 / 2}(\mathrm{SZA})$ for all of the SAPS events are shown in Fig. 6. The disturbed neutral winds correlate well with the $\mathrm{Ne}$ and $\cos ^{1 / 2}$ (SZA) with correlation coefficients of $>0.6$. The excellent correlation between $\cos ^{1 / 2}$ (SZA) and the westward neutral wind velocities in both hemispheres highlights the importance of solar illumination in explaining the UT effect of SAPS on the disturbance zonal neutral winds; that is, with more solar illumination and a subsequently larger $\mathrm{Ne}$ in the subauroral region, stronger disturbance neutral winds can be generated.

One may notice that the correlation coefficient between the disturbance neutral wind velocity and the electron density is stronger $(R=-0.9)$ in the Southern Hemisphere than that $(R=-0.6)$ in the Northern Hemisphere, which might be due to the larger displacement between the geomagnetic and geographic poles in the Southern Hemisphere than in the Northern Hemisphere. Thus, the UT variation of the solar illumination in the Southern Hemisphere is stronger than that in the Northern Hemisphere. The correlation between the disturbance neutral wind and $\mathrm{Ne}$ is moderate $(R=-0.6)$ in the Northern Hemisphere, which might be for the following reasons. The Ne used for the correlation study is the peak density in the subauroral region during SAPS periods, which might not fully represent the variation in the ion drag force. The ion drag force in the zonal direction is $\mathrm{Ne} v_{\text {in }}(V-U)$, where $v_{\text {in }}$ is collision frequency and $V$ and $U$ are ion and neutral velocity in the zonal direction. The correlation between the disturbance neutral wind velocity and the disturbance $\mathrm{Ne}(V-U)$ can be improved to 0.7 in the Northern Hemisphere. Another reason might be that there are other factors that can affect the zonal neutral wind. SAPS can affect the neutral winds in two ways: (1) a direct ion drag effect that drives the neutrals westward; (2) frictional heating that changes the air pressure and global wind circulation. The frictional heating can heat the neutrals and ions locally. Through thermal expansion and upwelling of the thermosphere, the heat can be transported globally through nonlinear dynamic processes. This is consistent with W. Wang et al. (2012) in that the neutral temperature was enhanced inside the polar cap by about $40 \mathrm{~K}$ through compressional heating caused by SAPS. The equatorward neutral wind turns westward at subauroral regions as a result of the Coriolis force. The additional role of the global circulation effect caused by SAPS might explain partly the moderate linear correlation between the zonal neutral wind and electron density.

\subsection{SAPS effects on Ne and $\rho$}

The strong SAPS-related plasma drifts and frictional heating can enhance the neutral and ion temperatures. Due to the upwelling of the thermosphere the mass density of the air can be enhanced at higher altitudes. The upwelling of molecular-rich air can enhance the plasma recombination rate. The plasma transportation due to SAPS can bring plasma from nighttime to daytime. Both the increased recombination rates and plasma transportation can result in a depletion in the ionospheric plasma density in the midlatitude trough (Anderson et al., 2001). Previous studies have reported that SAPS can deepen the mid-latitude density trough and form an air mass density bulge at $400 \mathrm{~km}$ altitudes (Moffett et al., 1992; Pintér et al., 2006; H. Wang et al., 2011, 2012b). By imposing an intense westward ion drift on a closed subauroral plasma tube, Moffett et al. (1992) found that the ion-neutral frictional heating increased the ion temperature and caused $F$ region plasma density to decrease due to the enhanced loss by chemical reactions and westward transportation. By implying a $2 \mathrm{~h}$ poleward electric field in the dusk sector at subauroral region in the 

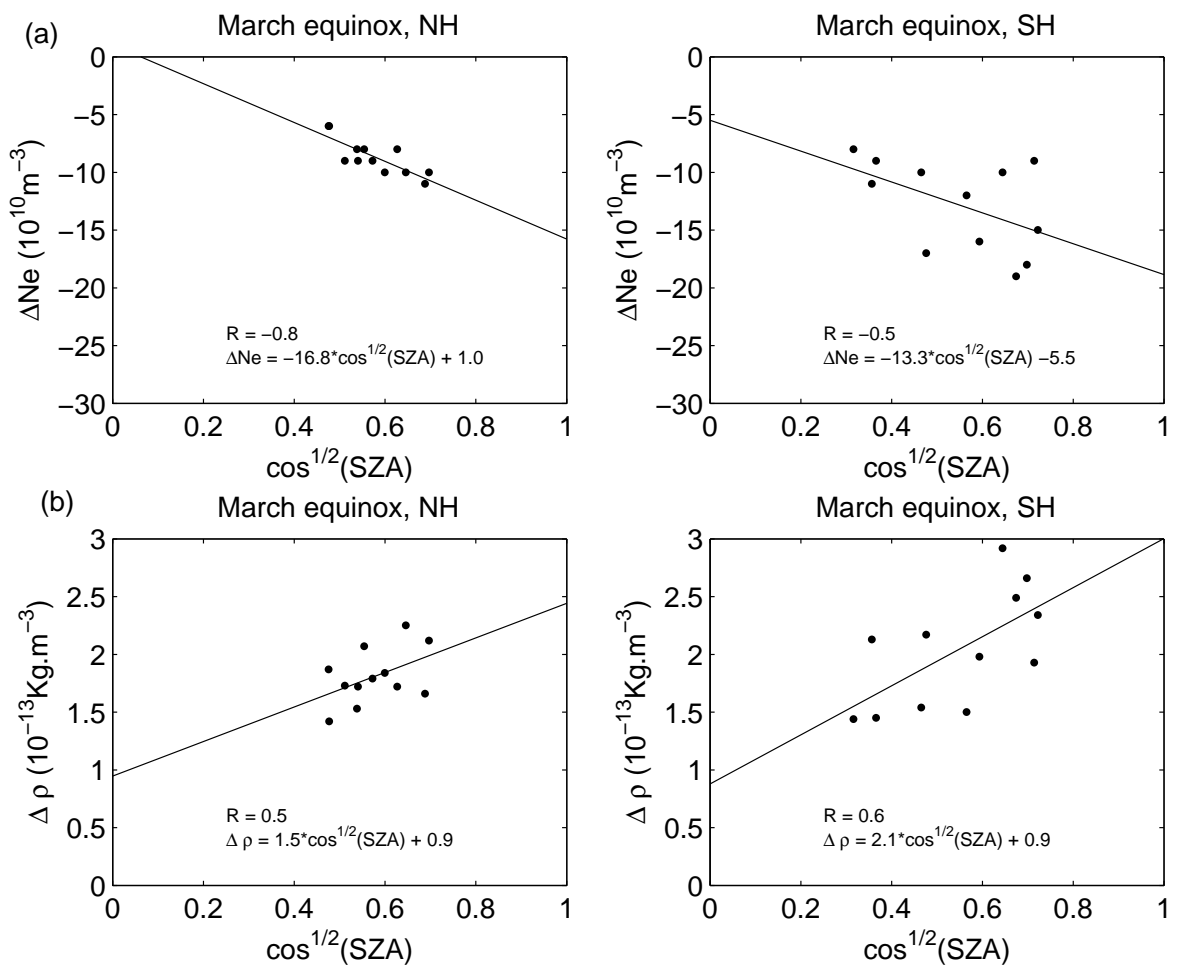

Figure 7. The top row shows a correlation analysis of the largest disturbance electron density at subauroral latitude with $\cos ^{1 / 2}(\mathrm{SZA})$ in both hemispheres. The bottom row shows a correlation analysis between the peak disturbance air mass density with cos ${ }^{1 / 2}(\mathrm{SZA})$ in both hemispheres. The correlation coefficient $(R)$ and linear relationship between the parameters are shown in each plot.
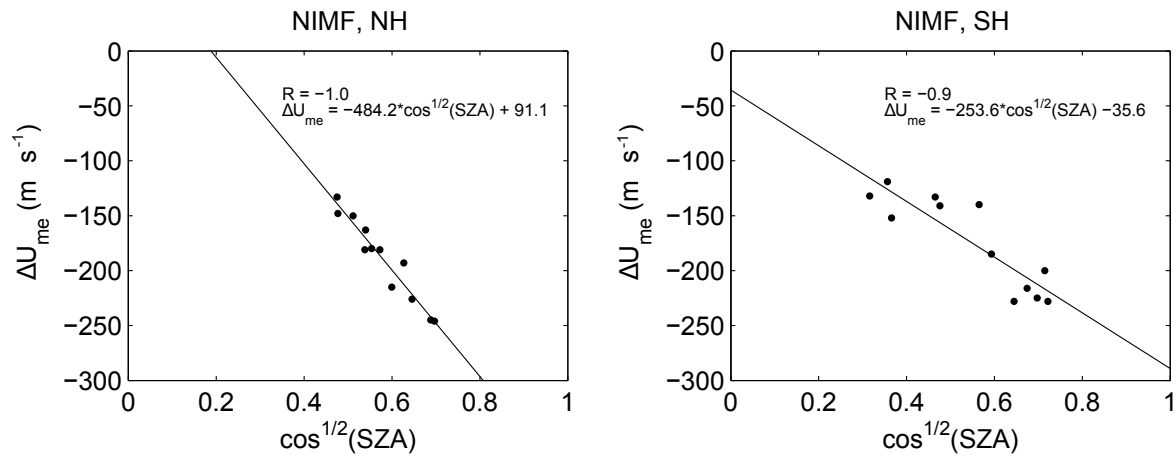

Figure 8. A correlation analysis of the strongest westward disturbance neutral wind with $\cos ^{1 / 2}(\mathrm{SZA})$ in both hemispheres during northward IMF periods. The correlation coefficient $(R)$ and linear relationship between the parameters are shown in each plot.

Sheffield Coupled Thermosphere-Ionosphere-Plasmasphere (CTIP), Pintér et al. (2006) showed that SAPS caused a decrease in the $F$ region peak density and an increased $\mathrm{O}^{+}$loss through chemical reactions. Based on CHAMP observations, H. Wang et al. (2011) found that large SAPS-induced neutral winds could heat the upper thermosphere and cause a $10 \%$ increase in the mass density (with respect to periods without SAPS) at an altitude of $400 \mathrm{~km}$. The density peak occurred in the same location as the SAPS peak, which indicated efficient thermospheric heating from the ion and neutral friction.
Through simulations, W. Wang et al. (2012) also found that SAPS contributed to deeper and more extended ionospheric electron density depletions at the subauroral latitudes. The interesting result in the present work is that there are UT variations in the SAPS' effect on the disturbance of the electron density and air mass density, consistent with that of the disturbance neutral winds. Figure 7 shows the correlations between $\cos ^{1 / 2}(\mathrm{SZA})$ and $\Delta \mathrm{Ne}$ and $\Delta \rho$ at subauroral regions. Figure 7 has the same format as Fig. 6. Here, $\Delta \mathrm{Ne}$ and $\Delta \rho$ are the peak disturbance electron and air mass densities for 
(a) $\mathrm{NH}$, duskside (12-24 MLT)

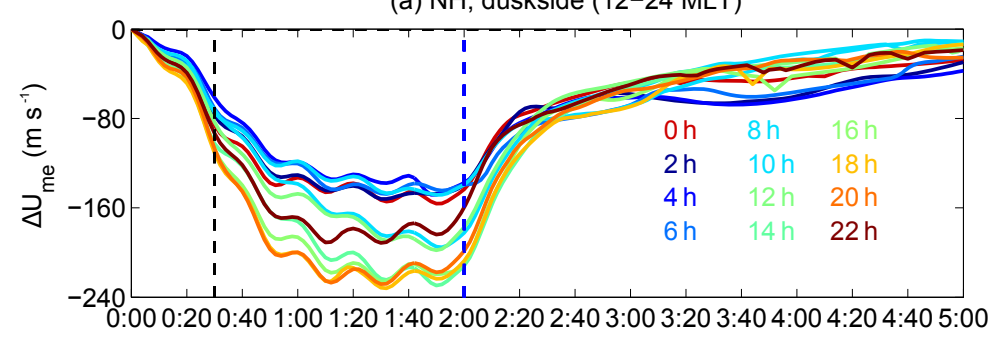

(b) $\mathrm{SH}$, duskside (12-24 MLT)

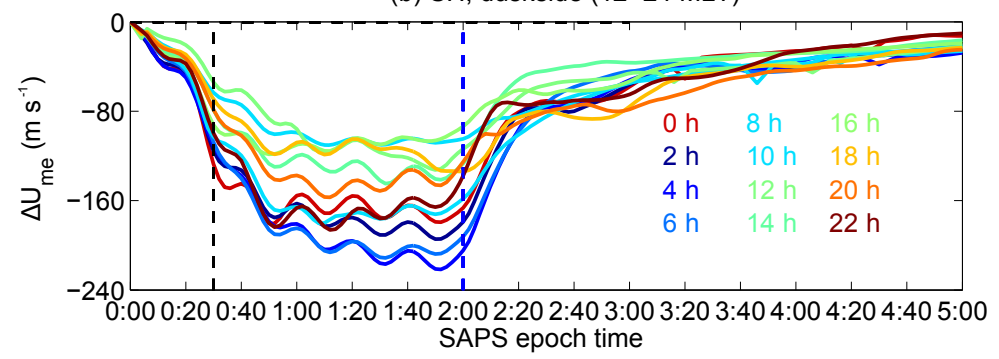

Figure 9. Time variation of the strongest disturbance neutral wind in the dusk sector (18:00-24:00 MLT). A sine-wave oscillation with a 20 min time period and $8 \mathrm{kV}$ amplitude is added to the SAPS peak potential in the steady case. Different colors represent SAPS onset times at $2 \mathrm{~h}$ intervals from 00:00 to 22:00 UT. The SAPS potential in the steady case attains extreme values around 00:30 epoch time, as indicated by the black vertical dashed line. SAPS become zero around 02:00 epoch time, as indicated by the blue vertical line. The top panel is for the Northern Hemisphere, and the bottom panel is the Southern Hemisphere.
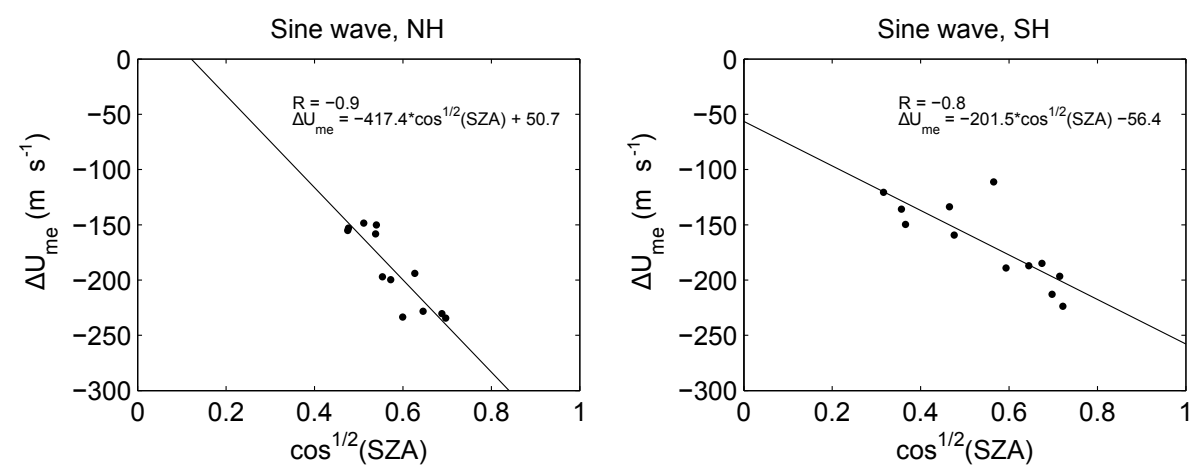

Figure 10. A correlation analysis of the strongest disturbance westward neutral wind at subauroral latitude with $\cos ^{1 / 2}(\mathrm{SZA})$ in both hemispheres for the sine-wave oscillation case. The correlation coefficient $(R)$ and linear relationship between the parameters are shown in each plot.

each SAPS event. There are correlations among these parameters, with correlation coefficients from 0.5 and upward. This indicates that with more sunlight, a larger decrease in $\mathrm{Ne}$ and a larger increase in the air mass density are produced in the SAPS region.

The correlations are moderate for $\Delta \rho$ and $\cos ^{0.5}(\mathrm{SZA})$ in the Northern Hemisphere $(R=0.5)$ and for both $\Delta \mathrm{Ne}$ and $\Delta \rho$ in the Southern Hemisphere $(R=-0.5$ and -0.6$)$. This implies that there are other factors in addition to solar illumination that can have effects on the depletion of electron densities and enhancement of neutral densities. The electron density can be reduced by a combination of several processes: SAPS-related westward transportation, recombi- nation due to enhanced $\mathrm{O}^{+}$, and vertical transport from disturbance neutral winds. The disturbance neutral winds can cause vertical motion of the plasma at subauroral latitudes under non-zero geomagnetic declination and inclination angle conditions at mid-latitudes. The $F$ region $\mathrm{Ne}$ can be increased due to upward motion as the recombination rate is reduced at higher altitudes. Conversely the $F$ region densities can be decreased by downward motion of plasma into regions of higher recombination rates. H. Wang et al. (2015) showed that the neutral wind-geomagnetic declination mechanism could cause larger longitudinal or UT variations in the $\Delta \mathrm{Ne}$ in the Southern Hemisphere than in the Northern Hemisphere, as the longitudinal differences in the geomag- 
netic declination were larger in the Southern Hemisphere, where the vertical transport from the neutral winds was more effective. We believe this might explain the weaker correlation between $\Delta \mathrm{Ne}$ and $\cos ^{1 / 2}(\mathrm{SZA})$ in the Southern Hemisphere than in the Northern Hemisphere. The frictional heating is proportional to the ionospheric conductivity, which can cause the enhancement of $\rho$ at higher altitudes. There is an inverse relationship between the ionospheric conductivity and Earth's dipole moment. It is known that the magnetic field strength shows obvious longitudinal differences in the two hemispheres. There are two peaks, which are located around $120^{\circ} \mathrm{W}$ and $120^{\circ} \mathrm{E}$ GLon, respectively, in the Northern Hemisphere. And there is only one peak, which is located around $140^{\circ}$ E GLon, in the Southern Hemisphere. The longitudinal variation of geomagnetic field strength can complicate the UT and longitudinal effect of frictional heating, and make the correlation between the solar illumination and the air mass density less excellent than expected.

\subsection{Northward IMF conditions}

In this section, we check the UT variations of SAPS effects on zonal neutral winds during a northward IMF period (IMF $B_{\mathrm{Z}}=2 \mathrm{nT}$ ). The regular high-latitude two-cell pattern during southward IMF periods turned into a four-cell pattern under the northward IMF condition (Crowley et al., 1992). The SAPS potentials were added in the same way as performed during the southward IMF period. The correlations between the disturbance zonal neutral winds and $\cos ^{1 / 2}(\mathrm{SZA})$ are shown in Fig. 8 in the two hemispheres. Good correlation can be found between these two parameters, indicating that the UT effect of SAPS on the disturbance zonal neutral wind velocities in relation to the solar illumination also exists under the northward IMF condition. However, the disturbance zonal neutral winds and the peak electron densities during SAPS periods are not well correlated in both hemispheres (figures not shown). The background convection at high latitude might be an important component in modulating the $\mathrm{F}$ layer electron density at mid-latitudes, which needs to be verified by observational studies. However, there are quite a few observational studies concerning SAPS effects on the ionosphere and thermosphere system during northward IMF periods. Horvath and Lovell (2016) investigated SAPS' impacts on the mid-latitude trough and auroral regions during the 2122 January 2005 geomagnetic storm during southward and northward IMF periods in the American sector. They found that the polar cap became a low plasma density region under the sunward convection condition, and the mid-latitude trough was more unstructured during northward IMF. Sojka et al. (2004) applied the SAPS electric field to the Utah State University time-dependent ionospheric model in order to assess the effect of the SAPS on the mid-latitude nighttime $F$ region ionosphere during southward IMF periods. They tested for different background convection patterns: one is the Volland symmetric two-cell pattern, the other is the H-
M pattern (Heppner and Maynard, 1987). They found different density features with the Volland convection pattern from those with an H-M background. Thoroughly examining SAPS effects on the thermosphere and ionosphere under northward IMF conditions will be conducted in the future by using both observations and simulations.

\subsection{Temporal variation of SAPS}

In the above section, the SAPS potential is changed linearly and held constant throughout its period of existence. However, previous work has reported the temporal variation of SAPS. Oksavik et al. (2006) reported that SAPS fluctuated on timescales of minutes between $500 \mathrm{~m} \mathrm{~s}^{-1}$ and $2 \mathrm{~km} \mathrm{~s}^{-1}$, for example, the increase from $0.4 \mathrm{~km} \mathrm{~s}^{-1}$ at 03:10 UT to $1.4 \mathrm{~km} \mathrm{~s}^{-1}$ at 05:20 UT, the increase from $1.3 \mathrm{~km} \mathrm{~s}^{-1}$ at 02:50 UT to $2.5 \mathrm{~km} \mathrm{~s}^{-1}$ at 03:10 UT, or the increase from $0.8 \mathrm{~km} \mathrm{~s}^{-1}$ at 03:50 UT to $1.8 \mathrm{~km} \mathrm{~s}^{-1}$ at 04:00 UT. Rapidly changing electric fields have been observed by incoherent scatter radars at Millstone Hill and Irkutsk research radar (Mishin et al., 2003; Foster et al., 2004). The GITM can update its electric field approximately every $2 \mathrm{~s}$, but typically does it every minute (Deng and Ridley, 2007). Thus, the GITM can be run using idealized conditions to study the response of the system to the input temporal fluctuations.

In this section, the SAPS potential changes such that the average potential is the same as in the previous section, but it oscillates in time. A simple sine-wave variation with a $20 \mathrm{~min}$ time period and $8 \mathrm{kV}$ amplitude was added to the SAPS peak potential: $A \cdot \sin (2 \pi t / T)$, where $A=8 \mathrm{kV}$, and $T=20 \mathrm{~min}$. All input parameters were the same as the southward IMF case, except for the SAPS potential. This causes wave-like oscillations in the SAPS velocity with the amplitude changing by about $500 \mathrm{~m} \mathrm{~s}^{-1}$ in the time range of $10 \mathrm{~min}$ (figure not shown). Figure 9 shows the temporal variation of the westward neutral winds with SAPS epoch time, which is in the same format as Fig. 4. Different colors denote SAPS events that occur at different UT times. There are obvious wave oscillations in the disturbance zonal neutral wind velocities with oscillation periods of $20 \mathrm{~min}$. There are phase differences of about $5 \mathrm{~min}$ between the plasma and neutral wind peak velocities. The peak disturbance zonal neutral winds are recorded for all SAPS runs that occur at different UTs. Figure 10 shows the correlation between the disturbed zonal neutral winds and $\cos ^{1 / 2}$ (SZA) in both hemispheres. Generally good correlations can be found between the disturbance zonal neutral wind velocities and $\cos ^{1 / 2}$ (SZA) in both hemispheres. This implies that for the sine-wave case, the SAPS effects on the neutral winds also exhibit UT variations in association with the solar illumination condition.

In order to quantitatively differentiate the steady and sinewave cases, we have calculated the averages and SDs of these strongest disturbance zonal neutral wind velocities (as shown in Figs. 6 and 10). The average neutral wind velocities are -183.9 and $-190.2 \mathrm{~m} \mathrm{~s}^{-1}$ for the steady and sine- 
wave cases in the Northern Hemisphere, and -165.6 and $-167.1 \mathrm{~m} \mathrm{~s}^{-1}$ in the Southern Hemisphere. The SDs are 28.8 and $35.7 \mathrm{~m} \mathrm{~s}^{-1}$ in the Northern Hemisphere, and 37.7 and $37.1 \mathrm{~m} \mathrm{~s}^{-1}$ in the Southern Hemisphere. The ratios of the deviations to the average velocities are thus 16 and $19 \%$ for the steady and sine-wave cases in the Northern Hemisphere, and 23 and $22 \%$ in the Southern Hemisphere. It can be seen that the average velocities are larger for the sine-wave case in both hemispheres than those for the steady case. Both the deviations and the deviation percentage of the average velocities are slightly larger for the sine-wave cases in the Northern Hemispheres, but comparable in the Southern Hemispheres. Thus, the UT effect is slightly larger for the sine-wave SAPS than the steady case in the Northern Hemisphere.

In this study, a simple sine-wave oscillation has been added to represent the temporal variation of SAPS, which might be different from real conditions. Mishin et al. (2002) provided observation of $10 \mathrm{~min}$ quasi-periodic variation of the SAPS electric field with $10 \mathrm{mV} \mathrm{m}^{-1}$ amplitude. Foster et al. (2004) reported large-scale $\left(30 \mathrm{mV} \mathrm{m}^{-1}\right)$ peak-to-peak wave-like oscillations in the SAPS electric field magnitude with 200 and 300 s periodicity. These small-scale structures of SAPS electric fields might derive from processes internal to the magnetosphere and ionosphere system, i.e., the subauroral ionospheric feedback instability (Streltsov and Foster, 2004). Horvath and Lovell (2016) further reported that SAPS wave structures might originate from Alfvén waves. Our future modeling work will investigate the effect of wave oscillations of SAPS on the thermosphere and ionosphere by including different frequencies and amplitude components.

\section{Conclusions}

By using a global ionosphere and thermosphere model, the temporal and spatial variations in the thermospheric zonal neutral winds in response to SAPS that start at different universal times (UT) are studied at $400 \mathrm{~km}$ altitude under a southward interplanetary magnetic field (IMF) condition. SAPS can drive westward neutral winds in the dusk sector in the SAPS region. These disturbance neutral winds exhibit large variations with UT during equinox conditions. With more solar illumination, stronger westward disturbance neutral winds are generated. The largest disturbance neutral winds occur at 18:00 UT in the Northern Hemisphere and at 04:00 UT in the Southern Hemisphere. The SAPS driven neutral winds tend to peak at earlier local times when there is less solar illumination, and at later local times when there is more solar illumination. The extent of the SAPS' effect on the deepening of the mid-latitude ionospheric trough and the enhancement of the air mass density shows UT variations in relation to the solar illumination. Obvious UT effects of SAPS on the neutral winds exist under northward IMF conditions and for a sine-wave oscillation case.
Code and data availability. We acknowledge the use of the GITM developed by the University of Michigan (Aaron Ridley, ridley@ umich.edu). Simulation data are available from the authors upon request.

Competing interests. The authors declare that they have no conflict of interest.

Acknowledgements. This work is supported by the National Nature Science Foundation of China (nos. 41674153, 41521063, and 41431073). The authors thank the reviewers for valuable suggestions regarding this work.

The topical editor, Keisuke Hosokawa, thanks three anonymous referees for help in evaluating this paper.

\section{References}

A, E., Ridley, A. J., Zhang, D., and Xiao, Z.: Analyzing the hemispheric asymmetry in the thermospheric density response to geomagnetic storms, J. Geophys. Res., 117, A08317, https://doi.org/10.1029/2011JA017259, 2012.

Anderson, P. C., Heelis, R. A., and Hanson, W. B.: The ionospheric signatures of rapid subauroral ion drifts, J. Geophys. Res., 96, 5785-5792, 1991.

Anderson, P. C., Carpenter, D. L., Tsuruda, K., Mukai, T., and Rich, F. J.: Multisatellite observations of rapid subauroral ion drifts (SAID), J. Geophys. Res., 106, 29585-29599, https://doi.org/10.1029/2001JA000128, 2001.

Blanc, M. and Richmond, A. D.: The ionospheric disturbance dynamo, J. Geophys. Res., 85, 1669-1686, https://doi.org/10.1029/JA085iA04p01669, 1980.

Califf, S., Li, X., Wolf, R. A., Zhao, H., Jaynes, A. N., Wilder, F. D., Malaspina, D. M., and Redmon, R.: Large-amplitude electric fields in the inner magnetosphere: Van Allen Probes observations of subauroral polarization streams, J. Geophys. Res., 121, 52945306, https://doi.org/10.1002/2015JA022252, 2016.

Clausen, L. B. N., Baker, J. B. H., Ruohoniemi, J. M., Greenwald, R. A., Thomas, E. G., Shepherd, S. G., Talaat, E. R., Bristow, W. A., Zheng, Y., Coster, A. J., and Sazykin, S.: Large-scale observations of a subauroral polarization stream by midlatitude SuperDARN radars: instantaneous longitudinal velocity variations, J. Geophys. Res., 117, A05306, https://doi.org/10.1029/2011JA017232, 2012.

Crowley, G., Cannon, P. S., Dozois, C. G., Reinisch, B. W., and Buchau, J.: Polar cap convection for B(z) northward, Geophys. Res. Lett., 19, 657-660, https://doi.org/10.1029/92GL00395, 1992.

Deng, W., Killeen, T. L., Burns, A. G., Roble, R. G., Slavin, J. A., and Wharton, L. E.: The effects of neutral inertia on ionospheric currents in the high-latitude thermosphere following a geomagnetic storm, J. Geophys. Res., 98, 7775-7790, https://doi.org/10.1029/92JA02268, 1993.

Deng, Y. and Ridley, A. J.: Dependence of neutral winds on convection E-field, solar EUV, and auroral particle precipitation at high latitudes, J. Geophys. Res., 111, A09306, https://doi.org/10.1029/2005JA011368, 2006. 
Deng, Y. and Ridley, A. J.: Possible reasons for underestimating Joule heating in global models: E field variability, spatial resolution, and vertical velocity, J. Geophys. Res., 112, A09308, https://doi.org/10.1029/2006JA012006, 2007.

Deng, Y., Huang, Y., Wu, Q., Noto, J., Drob, D., and Kerr, R. B.: Comparison of the neutral wind seasonal variation from midlatitude conjugate observations, J. Geophys. Res., 119, 3029-3035, https://doi.org/10.1002/2013JA019716, 2014.

Emmert, J. T., Fejer, B. G., Fesen, C. G., Shepherd, G. G., and Solheim, B. H.: Climatology of middle- and low-latitude daytime $\mathrm{F}$ region disturbance neutral winds measured by Wind Imaging Interferometer (WINDII), J. Geophys. Res., 106, 24701-24712, https://doi.org/10.1029/2000JA000372, 2001.

Emmert, J. T., Fejer, B. G., Shepherd, G. G., and Solheim, B. H.: Altitude dependence of middle and low-latitude daytime thermospheric disturbance winds measured by WINDII, J. Geophys. Res., 107, 1483, https://doi.org/10.1029/2002JA009646, 2002.

Emmert, J. T., Faivre, M. L., Hernandez, G., Jarvis, M. J., Meriwether, J. W., Niciejewski, R. J., Sipler, D. P., and Tepley, C. A.: Climatologies of nighttime upper thermospheric winds measured by ground-based Fabry-Perot interferometers during geomagnetically quiet conditions: 1. Local time, latitudinal, seasonal, and solar cycle dependence, J. Geophys. Res., 111, A12302, https://doi.org/10.1029/2006JA011948, 2006a

Emmert, J. T., Hernandez, G., Jarvis, M. J., Niciejewski, R. J., Sipler, D. P., and Vennerstrom, S.: Climatologies of nighttime upper thermospheric winds measured by ground-based Fabry-Perot interferometers during geomagnetically quiet conditions: 2. High-latitude circulation and interplanetary magnetic field dependence, J. Geophys. Res., 111, A12303, https://doi.org/10.1029/2006JA011949, 2006b.

Emmert, J. T., Richmond, A. D., and Drob, D. P.: A computationally compact representation of Magnetic-Apex and Quasi-Dipole coordinates with smooth base vectors, J. Geophys. Res., 115, A08322, https://doi.org/10.1029/2010JA015326, 2010.

Foster, J. C. and Vo, H. B.: Average characteristics and activity dependence of the subauroral polarization stream, J. Geophys. Res., 107, 1475, https://doi.org/10.1029/2002JA009409, 2002.

Foster, J. C., Erickson, P. J., Lind, F. D., and Rideout, W.: Millstone Hill coherent-scatter radar observations of electric field variability in the sub-auroral polarization stream, Geophys. Res. Lett., 31, L21803, https://doi.org/10.1029/2004GL021271, 2004.

Fuller-Rowell, T. J. and Evans, D. S.: Height-integrated Pedersen and Hall conductivity patterns inferred from the TIROSNOAA satellite data, J. Geophys. Res., 92, 7606-7618, https://doi.org/10.1029/JA092iA07p07606, 1987.

Fuller-Rowell, T. J., Codrescu, M. V., Moffett, R. J., and Quegan, S.: Response of the thermosphere and ionosphere to geomagnetic storms, J. Geophys. Res., 99, 3893-3914, https://doi.org/10.1029/93JA02015, 1994.

Galperin, Y., Ponomarev, V. N., and Zosimova, A. G.: Plasma convection in the polar ionosphere, Ann. Geophys., 30, 1-7, 1974.

Hagan, M. E., Burrage, M. D., Forbes, J. M., Hackney, J., Randel, W. J., and Zhang, X.: GSWM-98: results for migrating solar tides, J. Geophys. Res., 104, 6813-6828, https://doi.org/10.1029/1998JA900125, 1999.

He, F., Zhang, X.-X., and Chen, B.: Solar cycle, seasonal, and diurnal variations of subauroral ion drifts: statistical results, J. Geophys. Res., 119, 5076-5086, https://doi.org/10.1002/2014JA019807, 2014.

He, F., Zhang, X.-X., Wang, W., and Wan, W.: Different evolution patterns of Subauroral Polarization Streams (SAPS) during intense storms and quiet time substorms, Geophys. Res. Lett., 44, 10, https://doi.org/10.1002/2017GL075449, 2017.

Heppner, J. P. and Maynard, N. C.: Empirical high-latitude electric field models, J. Geophys. Res., 92, 4467-4489, https://doi.org/10.1029/JA092iA05p04467, 1987.

Horvath, I. and Lovell, B. C.: Structured subauroral polarization streams and related auroral undulations occurring on the storm day of 21 January 2005, J. Geophys. Res., 121, 1680-1695, https://doi.org/10.1002/2015JA022057, 2016.

Koustov, A., Nishitani, N., Ebihara, Y., Kikuchi, T., Hairston, M. R., and Andre, D.: Subauroral polarization streams: observations with the Hokkaido and King Salmon SuperDARN radars and modeling, Ann. Geophys., 26, 3317-3327, https://doi.org/10.5194/angeo-26-3317-2008, 2008.

Kunduri, B. S. R., Baker, J. B. H., Ruohoniemi, J. M., Clausen, L. B. N., Grocott, A., Thomas, E. G., Freeman, M. P., and Talaat, E. R.: An examination of inter-hemispheric conjugacy in a subauroral polarization stream, J. Geophys. Res., 117, A08225, https://doi.org/10.1029/2012JA017784, 2012.

Kunduri, B. S. R., Baker, J. B. H., Ruohoniemi, J. M., Thomas, E. G., Shepherd, S. G., and Sterne, K. T.: Statistical characterization of the large-scale structure of the subauroral polarization stream, J. Geophys. Res., 122, 6035-6048, https://doi.org/10.1002/2017JA024131, 2017.

Liu, X. and Ridley, A.: A simulation study of the thermosphere mass density response to substorms using GITM, J. Geophys. Res., 120, 7987-8001, https://doi.org/10.1002/2014JA020962, 2015.

Lühr, H., Häusler, K., and Stolle, C.: Longitudinal variation of $\mathrm{F}$ region electron density and thermospheric zonal wind caused by atmospheric tides, Geophys. Res. Lett., 34, L16102, https://doi.org/10.1029/2007GL030639, 2007.

Maus, S., Macmillan, S., Chernova, T., Choi, S., Dater, D., Golovkov, V., Lesur, V., Lowes, F., Lühr, H., Mai, W., McLean, S., Olsen, N., Rother, M., Sabaka, T., Thomson, A., and Zvereva, T.: The 10th generation international geomagnetic reference field, Phys. Earth Planet. In., 151, 320-322, https://doi.org/10.1016/j.pepi.2005.03.006, 2005.

McCormac, F. G. and Smith, R. W.: The influence of the interplanetary magnetic field $\mathrm{Y}$ component on the ion and neutral motions in the polar thermosphere, Geophys. Res. Lett., 11, 935938, 1984.

Miller, N. J., Brace, L. H., Spencer, N. W., and Carignan, G. R.: DE 2 observations of disturbances in the upper atmosphere during a geomagnetic storm, J. Geophys. Res., 95, 21017-21031, https://doi.org/10.1029/JA095iA12p21017, 1990.

Mishin, E., Nishimura, Y., and Foster, J.: SAPS/SAID revisited: a causal relation to the substorm current wedge, J. Geophys. Res., 122, 8516-8535, https://doi.org/10.1002/2017JA024263, 2017.

Mishin, E. V., Foster, J. C., Potekhin, A. P., Rich, F. J., Schlegel, K., Yumoto, K., Taran, V. I., Ruohoniemi, J. M., and Friedel, R.: Global ULF disturbances during a stormtime substorm on 25 September 1998, J. Geophys. Res., 107, 1486, https://doi.org/10.1029/2002JA009302, 2002.

Mishin, E. V., Burke, W. J., Huang, C. Y., and Rich, F. J.: Electromagnetic wave structures within subauroral 
polarization streams, J. Geophys. Res., 108, 1309, https://doi.org/10.1029/2002JA009793, 2003.

Moffett, R. J., Heelis, R. A., Sellek, R., and Bailey, G. J.: The temporal evolution of the ionospheric signatures of subauroral ion drifts, Planet. Space Sci., 40, 663-670, https://doi.org/10.1016/0032-0633(92)90007-B, 1992.

Oksavik, K., Greenwald, R. A., Ruohoniemi, J. M., Hairston, M. R., Paxton, L. J., Baker, J. B. H., Gjerloev, J. W., and Barnes, R. J.: First observations of the temporal/spatial variation of the sub-auroral polarization stream from the SuperDARN Wallops HF radar, Geophys. Res. Lett., 33, L12104, https://doi.org/10.1029/2006GL026256, 2006.

Pawlowski, D. J. and Ridley, A. J.: Modeling the thermospheric response to solar flares, J. Geophys. Res., 113, A10309, https://doi.org/10.1029/2008JA013182, 2008.

Perlongo, N. J. and Ridley, A. J.: Universal time effects in the responseo of the thermosphere to electric field changes, J. Geophys. Res., 121, 3681-3698, https://doi.org/10.1002/2015JA021636, 2016.

Pintér, B., Thom, S. D., Balthazor, R., Vo, H., and Bailey, G. J.: Modeling subauroral polarization streams equatorward of the plasmapause footprints, J. Geophys. Res., 111, A10306, https://doi.org/10.1029/2005JA011457, 2006.

Richmond, A. D.: Ionospheric electrodynamics using magnetic apex coordinates, J. Geomagn. Geoelectr., 47, 191-212, 1995.

Richmond, A. D. and Matsushita, S.: Thermospheric response to a magnetic substorm, J. Geophys. Res., 80, 2839-2850, https://doi.org/10.1029/JA080i019p02839, 1975.

Richmond, A. D., Lathuillere, C., and Vennerstroem, S.: Wind in the high-latitude lower thermosphere: dependence on the interplanetary magnetic field, J. Geophys. Res., 108, https://doi.org/10.1029/2002JA009493, 2003.

Ridley, A. J.: A new formulation for the ionospheric cross polar cap potential including saturation effects, Ann. Geophys., 23, 35333547, https://doi.org/10.5194/angeo-23-3533-2005, 2005.

Ridley, A. J., Deng, Y., and Tóth, G.: The global ionosphere thermosphere model, J. Atmos. Terr. Phys., 68, 839-864, https://doi.org/10.1016/j.jastp.2006.01.008, 2006.

Rishbeth, H.: The effect of winds on the ionospheric F2-peak, J. Atmos. Terr. Phys., 29, 225-238, https://doi.org/10.1016/00219169(67)90192-4, 1967.

Ritter, P., Lühr, H., and Doornbos, E.: Substorm-related thermospheric density and wind disturbances derived from CHAMP observations, Ann. Geophys., 28, 1207-1220, https://doi.org/10.5194/angeo-28-1207-2010, 2010.

Roble, R. G., Dickinson, R. E., and Ridley, E. C.: Global circulation and temperature structure of thermosphere with highlatitude plasma convection, J. Geophys. Res., 87, 1599-1614, https://doi.org/10.1029/JA087iA03p01599, 1982.

Schunk, R. W. and Nagy, A. F.: Ionospheres: Physics, Plasma Physics, and Chemistry, Cambridge University Press, 2004.

Smiddy, M., Sagalyn, R., Shuman, B., Kelley, M. C., Burke, W., Rich, F., Hays, R., and Lai, S.: Intense poleward-directed electric fields near the ionospheric projection of the plasmapause, Geophys. Res. Lett., 4, 543-546, https://doi.org/10.1029/GL004i011p00543, 1977.

Sojka, J. J., David, M., Schunk, R. W., Foster, J. C., and Vo, H. B.: A modeling study of the F-region re- sponse to SAPS, J. Atmos. Terr. Phys., 66, 415-423, https://doi.org/10.1016/j.jastp.2003.11.003, 2004.

Spiro, R. W., Heelis, R. A., and Hanson, W. B.: Ion convection and the formation of the mid-latitude $\mathrm{F}$ region ionization trough, J. Geophys. Res., 83, 4255-4264, 1978.

Streltsov, A. V. and Foster, J. C.: Electrodynamics of the magnetosphere-ionosphere coupling in the nightside subauroral zone, Phys. Plasmas, 11, 1260-1267, https://doi.org/10.1063/1.1647139, 2004.

Thayer, J. P., Killeen, T. L., McCormac, F. G., Tschan, C. R., Ponthieu, J., and Spencer, N. W.: Thermospheric neutral wind signatures dependent on the east-west component of the interplanetary magnetic field for Northern and Southern Hemispheres as measured from Dynamics Explorer-2, Ann. Geophys., 5, 363-368, 1987.

Wang, H., Lühr, H., Ridley, A., Ritter, P., and Yu, Y.: Storm time dynamics of auroral electrojets: CHAMP observation and the Space Weather Modeling Framework comparison, Ann. Geophys., 26, 555-570, https://doi.org/10.5194/angeo-26-555-2008, 2008.

Wang, H., Lühr, H., Häusler, K., and Ritter, P.: Effect of subauroral polarization streams on the thermosphere: a statistical study, J. Geophys. Res., 116, A03312, https://doi.org/10.1029/2010JA016236, 2011.

Wang, H., Lühr, H., and Ma, S. Y.: The relation between subauroral polarization streams, westward ion fluxes, and zonal wind: seasonal and hemispheric variations, J. Geophys. Res., 117, A04323, https://doi.org/10.1029/2011JA017378, 2012a.

Wang, H., Lühr, H., Ritter, P., and Kervalishvili, G.: Temporal and spatial effects of subauroral polarization streams on the thermospheric dynamics, J. Geophys. Res., 117, A11307, https://doi.org/10.1029/2012JA018067, 2012b.

Wang, H., Ridley, A. J., and Zhu, J.: Theoretical study of zonal differences of electron density at midlatitudes with GITM simulation, J. Geophys. Res., 120, 2951-2966, https://doi.org/10.1002/2014JA020790, 2015.

Wang, H., Liu, D. W., and Zhang, J.: Vertical structure of longitudinal differences in electron densities at mid-latitudes, Sci. Bull., 61, 252-262, 2016.

Wang, H., Zhang, K. D., Wan, X., and Lühr, H.: Universal time variation of high-latitude thermospheric disturbance wind in response to a substorm, J. Geophys. Res., 122, 4638-4653, https://doi.org/10.1002/2016JA023630, 2017.

Wang, W., Talaat, E. R., Burns, A. G., Emery, B., Hsieh, S.y., Lei, J., and $\mathrm{Xu}, \mathrm{J} .:$ Thermosphere and ionosphere response to subauroral polarization streams (SAPS): model simulations, J. Geophys. Res., 117, A07301, https://doi.org/10.1029/2012JA017656, 2012.

Weimer, D. R.: Improved ionospheric electrodynamic models and application to calculating Joule heating rates, J. Geophys. Res., 110, A05306, https://doi.org/10.1029/2004JA010884, 2005.

Wu, Q., Noto, J., Kerr, R., Kapali, S., Riccobono, J., Wang, W., and Talaat, E. R.: First Palmer and Millstone Hill midlatitude conjugate observation of thermospheric winds, J. Geophys. Res., 119, 3016-3028, https://doi.org/10.1002/2013JA019062, 2014.

Xiong, C., Lühr, H., and Fejer, B. G.: Global features of the disturbance winds during storm time deduced from CHAMP observations, J. Geophys. Res., 120, 5137-5150, https://doi.org/10.1002/2015JA021302, 2015. 
Yeh, H.-C., Foster, J. C., Rich, F. J., and Swider, W.: Storm time electric field penetration observed at mid-latitude, J. Geophys. Res., 96, 5707-5721, 1991.

Yu, Y., Jordanova, V., Zou, S., Heelis, R., Ruohoniemi, M., and Wygant, J.: Modeling subauroral polarization streams during the 17 March 2013 storm, J. Geophys. Res., 120, 1738-1750, https://doi.org/10.1002/2014JA020371, 2015.

Zhang, S.-R., Erickson, P. J., Foster, J. C., Holt, J. M., Coster, A. J., Makela, J. J., Noto, J., Meriwether, J. W., Harding, B. J., Riccobono, J., and Kerr, R. B.: Thermospheric poleward wind surge at midlatitudes during great storm intervals, Geophys. Res. Lett., 42, 5132-5140, https://doi.org/10.1002/2015GL064836, 2015.

Zhang, S.-R., Erickson, P. J., Zhang, Y., Wang, W., Huang, C., Coster, A. J., Holt, J. M., Foster, J. F., Sulzer, M., and Kerr, R.: Observations of ion-neutral coupling associated with strong electrodynamic disturbances during the 2015 St. Patrick's Day storm, J. Geophys. Res., 122, 1314-1337, https://doi.org/10.1002/2016JA023307, 2017.
Zhang, X., Liu, L., and Liu, S.: Dependence of thermospheric zonal winds on solar flux, geomagnetic activity, and hemisphere as measured by CHAMP, J. Geophys. Res., 122, 8893-8914, https://doi.org/10.1002/2016JA023715, 2017.

Zhu, J. and Ridley, A. J.: The effect of background conditions on the ionospheric response to solar flares, J. Geophys. Res., 119, 5060-5075, https://doi.org/10.1002/2014JA019887, 2014. 